\title{
Chronotype, sleep quality and sleep duration in adult distance education: Not related to study progress
}

Citation for published version (APA):

Gijselaers, J., Kirschner, P. A., \& De Groot, R. (2015). Chronotype, sleep quality and sleep duration in adult distance education: Not related to study progress. Learning and Individual Differences, 44, 46-52.

https://doi.org/10.1016/j.lindif.2015.10.002

DOI:

10.1016/j.lindif.2015.10.002

Document status and date:

Published: 01/12/2015

Document Version:

Peer reviewed version

Document license:

CC BY-NC-ND

Please check the document version of this publication:

- A submitted manuscript is the version of the article upon submission and before peer-review. There can be important differences between the submitted version and the official published version of record. People interested in the research are advised to contact the author for the final version of the publication, or visit the DOI to the publisher's website.

- The final author version and the galley proof are versions of the publication after peer review.

- The final published version features the final layout of the paper including the volume, issue and page numbers.

Link to publication

\section{General rights}

Copyright and moral rights for the publications made accessible in the public portal are retained by the authors and/or other copyright owners and it is a condition of accessing publications that users recognise and abide by the legal requirements associated with these rights.

- Users may download and print one copy of any publication from the public portal for the purpose of private study or research.

- You may not further distribute the material or use it for any profit-making activity or commercial gain

- You may freely distribute the URL identifying the publication in the public portal.

If the publication is distributed under the terms of Article 25fa of the Dutch Copyright Act, indicated by the "Taverne" license above, please follow below link for the End User Agreement:

https://www.ou.nl/taverne-agreement

Take down policy

If you believe that this document breaches copyright please contact us at:

pure-support@ou.nl

providing details and we will investigate your claim.

Downloaded from https://research.ou.nl/ on date: 26 Apr. 2023 


\section{Chronotype, Sleep Quality and Sleep Duration in Adult Distance Education: Not Related to Study Progress}

Hieronymus J.M. Gijselaers ${ }^{1, *}$, Paul A. Kirschner ${ }^{1}$, Renate H.M. de Groot ${ }^{1,2}$

http://dx.doi.org/10.1016/j.lindif.2015.10.002

Author note

1: Welten Institute - Research Centre for Learning, Teaching and Technology, Open University of the Netherlands.

2: Maastricht University, Department of Complex Genetics, School for Nutrition, Toxicology and Metabolism (NUTRIM) / Faculty of Health, Medicine and Life Sciences, Maastricht, the Netherlands.

*: Corresponding author: Jérôme Gijselaers, Welten Institute, Open University of the Netherlands, P.O. Box 2960, 6401 DL Heerlen, The Netherlands. E-mail: Jerome.Gijselaers@ou.nl (present address) /

h.gijselaers@gmail.com (permanent address)

Paul A. Kirschner: Paul.Kirschner@ou.nl

Renate H.M. de Groot: Renate.deGroot@ou.nl 


\begin{abstract}
Research in traditional education shows chronotype, sleep duration and sleep quality to be related to learning performance. Research in adult students participating in distance education (DE) is scarce. This study aims to provide knowledge on these relationships in this educational setting. In an observational longitudinal study, chronotype, sleep duration (i.e., for work and free days separately) and sleep quality of 894 students were analyzed in a multiple regression analyses. Students provided information on sleep-related measures and important covariates at the start of their study and study progress was evaluated after 14 months (i.e., the number of successfully completed modules). In line with previous research, chronotype did not predict study progress. Further, sleep duration did not predict study progress, neither as a linear nor as a polynomial term. Third, sleep quality did not predict study progress. Concluding, these results are in line with previous research that DE provides a solution to the asynchrony problem. Findings regarding sleep duration and sleep quality are new and unexpected, asking for attention and further research. Despite the study’s observational nature, findings suggest that students participating in DE may benefit from this type of education as the asynchrony problem appears not to apply here, as students can choose their own study schedule.
\end{abstract}

Keywords: Online learning; Distance learning; Learning performance; The ALOUD study; Asynchrony problem 


\section{Introduction}

Sleep is essential for maintaining proper brain functioning (Cirelli \& Tononi, 2008). Insufficient sleep duration and/or quality has been shown to impair school performance in children and adolescents participating in traditional education (Carskadon, 1990; Dewald, Meijer, Oort, Kerkhof, \& Bögels, 2010). In addition, the idiosyncratic characteristic chronotype - whether you are a morning or an evening person - has been shown to be influencing school performance in adolescents in traditional education (Escribano, Díaz-Morales, Delgado, \& Collado, 2012). However, little research deals with the relation between chronotype, sleep duration, sleep quality and study progress in adult distance education (DE) students.

This population is important as life expectancy is increasing and the fastest growing group is that of older adults (The Netherlands: Centraal Bureau voor de Statistiek, 2014; Worldwide: United Nations, 2012). Retirement age policies are being upwardly revised and our knowledge-based economy is developing quickly; as a result people have to work and learn longer. To compensate for the increasing need to continue to develop professional knowledge and experience far into adult age (Eurydice, 2011), people often participate in formal continuing education. This adult population generally has to combine family and work responsibilities with their study, which is why they often choose for DE. DE increasingly uses Information and Communication Technologies allowing these students to study when and where they choose, often at a self-determined pace. This study was executed among students of this type of DE.

\subsection{Mechanisms}

There is no generally accepted scientific explanation of why we sleep (Cirelli \& Tononi, 2008). As research regarding learning progresses, processes become apparent that provide possible explanations. Recent scientific research shows that sleep promotes the consolidation of information acquired during the day (e.g., Diekelmann \& Born, 2010; Payne et al., 2012). Slow-wave sleep is especially important as this plays a role in the consolidation of hippocampus-dependent declarative memories. During slow-wave sleep these memories are reactivated and redistributed over networks in the neocortex (Born, 2010), which is important for learning (Ribeiro \& Stickgold, 2014). Deprivation of sleep leads to the activation of certain genes which indirectly negatively influence health and cognition. Chronic sleep deprivation adds to this and intensifies the negative effects of acute sleep deprivation on cognition (Möller-Levet et al., 2013), an indicator of performance on the complex measure of academic performance (Diamond, 2013; Furnham, Monsen, \& Ahmetoglu, 2009). 
However, research into the biological mechanisms of sleep - especially regarding sleep deprivation - is in the early stages and full understanding of the exact mechanisms is not possible at this point.

\subsection{Chronotype}

Chronotype is the behavioral reflection of one's underlying circadian rhythm, meaning, whether one is more a morning person or an evening person. Not only physiological factors such as hormone secretion and body core temperature fluctuate with chronotype. Chronotype also influences a broad range of cognitive capacities such as attention, executive functioning and memory (Schmidt, Collette, Cajochen, \& Peigneux, 2007). As cognitive performance is a reliable predictor for learning (Diamond, 2013) it is important to account for chronotype.

Chronotype can be measured using self-assessment (i.e., subjective) and sleep times (i.e., more objective, but still via reported sleep times). The first is considered a qualitative assessment, the latter a quantitative assessment (Roenneberg, Wirz-Justice, \& Merrow, 2003). These authors show that both of these measurements are in accordance with each other. Despite the congruency of these measures, it is important to recognize that these measures are different, despite that they aim to measure the same construct.

Chronotype changes over age. Children typically have a more early chronotype (Randler \& Truc, 2014), but in adolescence this shifts towards the evening as a result of reasons among which could be pubertal development (i.e., a delay in the secretion of melatonin in adolescence, Crowley, Acebo, \& Carskadon, 2007) and the need for functional autonomy (Díaz-Morales, Escribano, Jankowski, Vollmer, \& Randler, 2014). In adulthood, chronotype tends to shift back towards the morning type (Díaz Morales \& Sánchez-López, 2004).

In traditional education, chronotype has a profound influence on learning results. Such face-to-face programs start early in the morning giving early chronotypes an advantage. Evening types tend to get less sleep, awake later and skip breakfast compared to morning types. This leads to lower motivation, which affects school performance as an indirect effect (Boschloo et al., 2012). In addition, early chronotypes tend to achieve higher grades than late chronotypes (Randler \& Frech, 2009). In DE, however, no relationship between chronotype and performance has been found (Jovanovski \& Bassili, 2007). This could be because these students can choose a learning time better fitting their chronotype. A study in which morning and evening classes were implemented evaluated which chronotypes performed better in which class. The researchers found that morning types performed better in morning classes, compared to evening types and evening types better in evening classes, compared to morning types (Önder, Horzum, \& Beşoluk, 2011). The fact that no differences are observed between chronotype and performance in DE is due to the principles of DE. It allows students to study anytime 
and anywhere, at their preferred biological time schedule, when their performance is high (Horzum, Önder, \& Beşoluk, 2014). However, despite that the education itself does not force an asynchrony on learning time in DE, asynchrony can still occur. Students can lack the ability to choose the proper learning time fitting their chronotype or their freedom to choose the preferred learning time is limited due to other life responsibilities (e.g., work and family responsibilities), which is often the case in adult DE students.

Lastly, it is important to recognize that chronotype influences sleep duration, depending on one’s social clock. Evening types, for example, may get too little sleep on weekdays because their social clock dictates they awaken early, though they go to bed late, because of their evening preference. On the other hand, morning types may get too little sleep on weekends when their social clock dictates a nice, but late, get-together Friday evening, resulting in less sleep as morning types wake up early, while evening types can easily sleep longer. Thus, chronotype has an impact on sleep duration, making it important to account for.

\subsection{Sleep duration and sleep quality}

The ideal sleep duration for adults is around 7-8 hours per night, with an inverse U-shaped relation between sleep duration and cognitive performance (Ferrie et al., 2011; Sternberg et al., 2013). Still, many adults get too little sleep as their social clock dictates them to get up early due to, for instance, work responsibilities or children; typical characteristics of DE students.

In traditional education, findings from both cross-sectional and experimental studies show that sleep deprivation (i.e., in the form of duration or quality) leads to poorer learning and lower academic performance (Curcio, Ferrara, \& De Gennaro, 2006; Gruber et al., 2014; Short, Gradisar, Lack, \& Wright, 2013). In DE, no research regarding the relation between sleep duration and learning performance is available. Though chronotype has been shown to influence sleep duration (Traditional education: Escribano et al., 2012; DE: Önder et al., 2011), it is still important to include sleep duration in the analyses, next to chronotype. This is especially true because DE students are not dictated by their social clock for their study; their study is selfregulated. This means that the shared variance of sleep duration and chronotype in relation to learning performance could be less, which makes sleep duration even more important for the analyses.

Sleep deprivation or impaired sleep quality negatively influences cognitive performance on a wide range of functions including executive attention, working memory, and higher order functions (Durmer \& Dinges, 2005). In traditional education, negative effects of sleep deprivation or poor sleep quality on learning performance have repeatedly been shown in children and adolescents (cf. review of Dewald et al., 2010). It has 
been found in 'emerging adults' (i.e., adults between 18-25 years old) that sleep quality is related to academic performance; specifically, lower sleep quality is related to lower academic performance (Radek \& Kaprelian, 2013). This is of interest, as the current study also includes these so-called 'emerging adults'. Only one study is available on the relationship between sleep quality and learning performance in adults participating in DE (Miles, 2014). There, a relation between sleep quality and test grade was found; the lower the sleep quality, the lower the test grade. Clarity is lacking in this study, as it appears that students could have been enrolled in different courses, however, this is unclear. If so, measuring learning performance with a grade would not be correct, as courses differ in terms of difficulty and content. These findings therefore ask for clarification and replication. Further, no research is available on the relationship between sleep quality and cognition in adults, to deduce possible hypotheses from. In contrast, much research is available on older adults (i.e., >65 years). However, there is only a small group of students in this age group in the current study. Because of this void in knowledge, it is highly interesting to investigate the combination of sleep duration and sleep quality in the adults in this study.

\subsection{The present study}

This study was executed among students of the Open University of the Netherlands (OUNL), an institute providing formal university-level DE to adults. The goal is to provide insight in the relation between chronotype, sleep duration and sleep quality on the one hand and study progress on the other, in adults participating in DE. Based on the findings presented above, we expected: (1) chronotype to be unrelated to study progress, as students can choose their own study schedule and are not dictated by a fixed class schedule; (2) sleep duration to show an inverted U-shaped relation with study progress (i.e., students with an optimal sleep duration tend to have a higher study progress); (3) sleep quality to be positively related to study progress (i.e., students with a better sleep quality tend to have a higher study progress). 


\section{Methods}

\subsection{Design}

Data from this observational study come from the Adult Learning Open University Determinants (ALOUD) study, an investigation of different psychological and biological factors possibly affecting study progress in DE students (Neroni, Gijselaers, Kirschner, \& de Groot, 2015). Collected measures in the ALOUD study not included in this article were other biological measures (i.e., physical activity and nutrition), cognition and psychological factors. Chronotype, sleep duration, sleep quality and covariates were reported via an online digital survey conducted after registration at the university. Study progress was measured objectively using data from the exam registration office.

\subsection{Participants}

During one year (Sept. 2012 - Aug. 2013), all new OUNL students who signed up for one or more regular bachelor or master course(s) were invited to participate. At the OUNL, students can register and start throughout the year as the education is modular and self-paced, open to everyone (with an age of at least 18 years old) and the curriculum is not fixed. The OUNL mainly delivers online education. The approached population size was 4945, 57.5\% ( $\mathrm{N}=2842)$ of whom responded and 41.3\% ( $\mathrm{N}=2041)$ of whom fully participated. Included in the analyses were all participants who fully completed the survey, attempted an exam (see below), participated within 9 weeks (see section 2.3), had no missing data and were not an outlier (see section 2.5).

Attrition rates in this population are high, as more than 50\% of the responders in the investigated population did not successfully complete any course after one year. As the goal is to predict study progress, including students without any study progress after 14 months could confound possible relations. However, excluding those without progress is not desirable as they may have studied, but without successfully finishing a course. To make a more valid data selection, an official examination attempt was used as a proxy of having studied. In this way, the high number of students that had bought a course but never attempted to officially finish it or who did not intend to attain course credits (i.e., buying the course purely out of interest) could be excluded. The information on exam attempts was provided by the exam registration office. 


\subsection{Procedures}

Participants were automatically invited to participate via the university e-mail system 14-21 days after successful registration. The 7-day range is because a bulk mailing was sent weekly. Students received an e-mail reminder 2 weeks after the initial invitation and 1 week later a final reminder. Four weeks after the initial invitation, a phone call was made (with attempts in the three subsequent weeks) asking potential participants whether they were interested in participating. If so, they received the original invitation once more when needed and a reminder 6.5 weeks after the initial invitation, which was around 1.5 weeks after the phone call. In case the phone call was made in week 6, the reminder was sent 1 week later. Participants only received reminders or a telephone call if no full response was recorded.

The survey was administered online using LimeSurvey®), version 1.92+ (LimeSurvey Project Team / Carsten Schmitz, 2012). Full participation cost the participants 45-60 minutes on average and it was possible to stop and continue later, allowing them more freedom to participate by spreading the time burden. Participants who fully participated could win (5\% chance) a gift voucher of $€ 20$. The ALOUD study was approved by the local ethical committee of the OUNL (cETO). Each participant signed a digital informed consent form, explicating the use of the personal data gathered, voluntary participation, withdrawal at any time, and their permission to use the data for the described goals. Participants had to click a check-box to agree with the terms mentioned; a mandatory action to start the survey.

\subsection{Materials}

\subsubsection{Dependent and independent measures}

The dependent measure was the participants’ objective study progress, operationalized as the number of successfully completed study modules in 14 months (i.e., the standard subscription period when registering for a course). A course at the OUNL consists of one or multiple modules. One module is equal to 4.3 European Credits (EC) in the European Credit Transfer System (ECTS). The nominal study load for one module is approximately 120 hours. The information from which the number of modules was derived came directly from the exam registration system of the OUNL. The independent measures were extracted from various questionnaires. Chronotype was measured via reported sleep- and wake-times on work and free days using specific questions from the Munich ChronoType Questionnaire (Roenneberg et al., 2003). Midsleep on free days corrected for sleep debt ( $\left.\mathrm{MSF}_{\mathrm{SC}}\right)$, was used as the measure for chronotype (Roenneberg et al., 2004). Sleep quality was measured with the Pittsburg Sleep Quality Index (PSQI), a well-known and well-validated self- 
report sleep quality measure (Buysse, Reynolds, Monk, Berman, \& Kupfer, 1989). The global PSQI score was dichotomized and used as indicator for sleep problems. A score higher than 5 was indicative of sleep problems (Aloba, Adewuya, Ola, \& Mapayi, 2007). Sleep duration was derived from the MCTQ (Roenneberg et al., 2003), for work and free days separately. The reported sleep and wake time were used to calculate sleep duration.

\subsubsection{Covariates}

In the online appendix, more information can be found regarding the covariates. The online appendix provides information on how and why these variables were measured, were they originated from and how they were calculated, if relevant. The covariates taken into account were: age; sex; number of working hours per week; expected average of number of study hours per week to be invested; nationality; native language; body mass index; level of education; computer abilities; study motive; study goal; alcohol consumption; and life satisfaction.

\subsection{Analyses}

Data were analyzed using multiple linear regression. A P-value below .05 was considered to be significant. Outliers on the variables of interest (i.e., independent variables) were excluded before analyses (i.e., a standardized Z-value higher than the absolute value of 3.29; Field, 2009, p. 26). A covariate model was built including all covariates, after which non-significant predictors were excluded following a backward stepwise method, yielding model A. Model B was tested by adding chronotype, sleep duration (i.e., for work and free days separately) and sleep quality to model A. Model C was tested by adding $2^{\text {nd }}$ degree terms (i.e., polynomial terms) for sleep duration to model B. All analyses were performed with SPSS (version 21; SPSS Inc., Chicago, IL, USA). 


\section{Results}

\subsection{Dataset compilation}

The original dataset contained 2842 cases. Participants were excluded if they: (1) did not attempt an exam as mentioned in section 2.2 (1236 cases); (2) did not complete the survey (410 cases); (3) did not participate within 9 weeks (32 cases); (4) had missing data in one of the sleep-related variables (254 cases); and (5) were classified as outliers as mentioned in section 2.5 (16 cases). All exclusions led to the analyses reported below with 894 respondents.

\subsection{Descriptives}

Close inspection of the distribution of the dependent variable revealed a binomial distribution. The positive skew and the variance-to-mean ratio being higher than 1 (i.e., 2.43) indicated overdispersion. Thus, along with assuming a negative binomial distribution, a parameter had to be estimated in the model to correct for overdispersion. To conclude, a generalized multiple linear regression was conducted to analyze the data, with a negative binomial distribution (i.e., the GENLIN function in SPSS).

The descriptives for interval variables are depicted in Table 1, the appendix also includes the range of all variables. The descriptives for dichotomous variables are depicted in Table 2. The assumption of no multicollinearity was met, following inspection of the correlations (see appendix) and the tolerances. A high correlation was present between the two dummy variables for educational level. High correlation was expected here because it concerns dummy variables. However, both the correlation as the tolerance estimates were still within limits (i.e., below .8 and above .4 respectively, according to Field, 2009), thus no multicollinearity was present. All predictors (i.e., covariates and independent variables) were included in the evaluation of this assumption (see appendix). 
Table 1. Descriptives of all included variables measured at interval level

\begin{tabular}{lcc}
\hline Variable & Mean & SD \\
\hline Study progress (successfully completed modules in 14 months) & 2.49 & 2.46 \\
Total work hours per week & 30.94 & 12.11 \\
Expected study hours per week & 12.30 & 6.48 \\
Age (years) & 36.15 & 10.45 \\
Body mass index ( $\left.\mathrm{kg} / \mathrm{m}^{2}\right)$ & 24.03 & 3.92 \\
Computer abilities (higher is better ability) & 42.72 & 5.81 \\
Expected number of completed modules & 2.26 & 2.29 \\
Total weekly alcohol consumption (standard glasses) & 3.11 & 4.61 \\
Life satisfaction (higher is higher satisfaction) & 25.48 & 5.43 \\
Sleep duration on work days (hours:minutes) & $7: 56$ & $0: 56$ \\
Sleep duration on work days (polynomial) & 0.88 & 1.46 \\
Sleep duration on free days (hours:minutes) & $8: 30$ & $1: 07$ \\
Sleep duration on free days (polynomial) & 1.23 & 1.89 \\
Chronotype (sleep debt corrected midsleep on free days; hours:minutes) & $3: 49$ & $0: 55$ \\
\hline
\end{tabular}

Table 2. Descriptives of all included variables measured at nominal or ordinal level

\begin{tabular}{|c|c|c|}
\hline Variable & Number & Percentage \\
\hline \multicolumn{3}{|l|}{ Sex } \\
\hline Male (0) & 328 & 36.7 \\
\hline Female (1) & 566 & 63.3 \\
\hline \multicolumn{3}{|l|}{ Nationality } \\
\hline Dutch (1) & 806 & 90.2 \\
\hline Non-Dutch (0) & 88 & 9.8 \\
\hline \multicolumn{3}{|l|}{ Native language } \\
\hline Dutch (1) & 848 & 94.9 \\
\hline Non-Dutch (0) & 46 & 5.1 \\
\hline \multicolumn{3}{|l|}{ Dummy educational level high } \\
\hline Educational level is high (1) & 434 & 48.5 \\
\hline Educational level is other $(0)$ & 460 & 51.5 \\
\hline \multicolumn{3}{|l|}{ Dummy educational level university } \\
\hline Educational level is university (1) & 321 & 35.9 \\
\hline Educational level is other $(0)$ & 573 & 64.1 \\
\hline \multicolumn{3}{|l|}{ Study motive } \\
\hline Personal (0) & 502 & 56.2 \\
\hline Professional (1) & 392 & 43.8 \\
\hline \multicolumn{3}{|l|}{ Sleep quality } \\
\hline Normal sleep & 426 & 47.7 \\
\hline Sleep problems & 468 & 52.3 \\
\hline
\end{tabular}

We hypothesized an inverted U-shape for the relation between sleep duration and study progress. To verify this we inspected the scatter plot of this relationship and confirmed our hypothesis. As linear regression assumes a linear relationship, a U-shaped relation needs to be corrected. To ensure the validity of our analyses, we therefore included sleep duration as a polynomial term. Sleep duration was centered and squared and then included in the model to ensure the modeled relation was linear. The formula for this term is $(\mathrm{x}-\mu)^{2}$. 


\subsection{Results of the analyses}

The results for the tested models can be found in Table 3. Every model was significantly better than the null model (i.e., the intercept-only model) as indicated by the chi-square measure reported in the table. Model A contained all significant covariates. Model B revealed that chronotype, sleep duration (i.e., for both work and free days) and sleep quality were not related to study progress. In model C, the polynomial terms for sleep duration were no significant predictor for study progress. This means that sleep duration is not related to study progress, also not in an inverted U-shaped relation.

In addition, the differences in chi-square between the model was investigated to evaluate whether model B or C predicted study progress better than model A. Both model B $\left(\chi^{2}(4, \mathrm{~N}=894)=2.721, \mathrm{p}=.60\right)$ and model $C\left(\chi^{2}(6, N=894)=3.627, p=.73\right)$ were not significantly better than model A. This means that the investigated sleep variables did not add significantly to the prediction of study progress.

Table 3. Results of the multiple linear regression analyses

\begin{tabular}{|c|c|c|}
\hline Predictor variable & $\begin{array}{c}\beta \\
\text { (standardized) }\end{array}$ & $\begin{array}{c}\text { Significance } \\
(p \text {-value })\end{array}$ \\
\hline \multicolumn{3}{|l|}{ Model A $\left(\chi^{2}=89.515, \mathrm{df}=5, \mathrm{p}<0.001\right)$} \\
\hline Expected study hours & .143 & $<.001$ \\
\hline Body mass index & -.108 & $<.001$ \\
\hline Expected number of completed modules after 6 months & .130 & $<.001$ \\
\hline Life satisfaction & .118 & $<.001$ \\
\hline Native language $^{1}$ & .461 & .003 \\
\hline \multicolumn{3}{|l|}{ Model B $\quad\left(\chi^{2}=92.236, \mathrm{df}=9, \mathrm{p}<0.001\right)$} \\
\hline Expected study hours & .143 & $<.001$ \\
\hline Body mass index & -.105 & $<.001$ \\
\hline Expected number of completed modules after 6 months & .131 & $<.001$ \\
\hline Life satisfaction & .115 & $<.001$ \\
\hline Native language $^{1}$ & .446 & .003 \\
\hline Chronotype & -.019 & .540 \\
\hline Sleep duration (work days) & .052 & .127 \\
\hline Sleep duration (free days) & -.013 & .708 \\
\hline Sleep quality ${ }^{1}$ & .013 & .833 \\
\hline \multicolumn{3}{|l|}{ Model $C \quad\left(\chi^{2}=93.142, \mathrm{df}=11, \mathrm{p}<0.001\right)$} \\
\hline Expected study hours & .146 & $<.001$ \\
\hline Body mass index & -.105 & $<.001$ \\
\hline Expected number of completed modules after 6 months & .130 & $<.001$ \\
\hline Life satisfaction & .113 & $<.001$ \\
\hline Native language $^{1}$ & .446 & .004 \\
\hline Chronotype & -.013 & .685 \\
\hline Sleep duration (work days) & .052 & .124 \\
\hline Sleep duration polynomial (work days) & -.015 & .617 \\
\hline Sleep duration (free days) & -.011 & .744 \\
\hline Sleep duration polynomial (free days) & -.020 & .518 \\
\hline Sleep quality ${ }^{1}$ & .012 & .847 \\
\hline
\end{tabular}

${ }^{1}$ These dichotomous variables were not standardized as this does not enhance interpretation 


\section{Discussion}

The purpose of this research was to investigate relations between sleep quality, sleep duration and chronotype on the one hand and study progress on the other in adult DE students. Previous research in this area is scarce and the combination of these three sleep related variables is new. One out of three hypotheses was confirmed in the analysis. First, chronotype was not predictive for study progress, in line with our hypothesis. Second, sleep duration was not predictive for study progress (i.e., neither for work of for free days), which was in opposition to our hypothesis. Third, sleep quality did not predict study progress, also in opposition to our hypothesis. These results will be discussed separately below.

In agreement with hypothesis 1 , chronotype was not related with study progress, replicating the few studies which have investigated this in DE (Horzum et al., 2014; Jovanovski \& Bassili, 2007; Önder et al., 2011). This finding is important in light of the asynchrony problem found in traditional education with its set time slots. In such learning situations, people with an evening preference suffer from the requirement to attend classes in the morning as their preferred biological time schedule does not align with the time schedule of the institution. This so-called asynchrony problem is not imposed by DE, where students mostly choose the time to learn themselves. The results indicate, that a lack of freedom and/or ability of students to choose the best time-of-day for learning also does not impose asynchrony. The results indicate that DE offers a solution to the asynchrony problem apparent in traditional education. In addition, it seems that students are able to choose the correct times to learn, fitting their chronotype. Important to note is that chronotype in this study was measured as a quantitative measure of circadian timing in the form of phase of entrainment.

Opposite to hypothesis 2, sleep duration was not predictive for study progress, neither as a linear term or as a polynomial term. This accounted for sleep duration on work days as well as free days. No research on the prediction of learning performance using sleep duration is available in a DE setting. This makes these findings highly interesting and a starting point for continuing research. When we compare these findings with research executed within a traditional educational setting, the findings of the current study do not align. In traditional education, sleep duration is clearly related to learning performance (e.g., Taylor, Vatthauer, Bramoweth, Ruggero, \& Roane, 2013). Especially interesting is that fact that these findings are not in line with research regarding cognitive performance as an outcome measure (Ferrie et al., 2011; Sternberg et al., 2013). Thus, it could well be that cognitive measures are not a strong predictor for learning performance in DE. This will be 
investigated in another study, published in the near future, with data from the ALOUD study (Neroni et al., 2015).

Sleep quality was not predictive for study progress, in contrast to hypothesis 3 . This finding does not align with the only other study in this population and field (Miles, 2014). In traditional education, in children and adolescents, from whom we extrapolated the hypothesis, poor sleep quality negatively affects learning performance (Dewald et al., 2010). It is known that sleep quality decreases with increasing age, influencing cognition negatively (Nebes, Buysse, Halligan, Houck, \& Monk, 2009). However, little is known about the effects of lower sleep quality on cognition in normal, non-disordered young and middle-aged adults. It could be that adults are less affected by sleep quality in comparison with children, adolescents and older adults, considering that our sample consisted of mainly middle-aged adults. The impact of sleep quality on cognition in this age group is not well investigated, making this finding highly interesting and demanding more in-depth investigation, considering the limitations of this study, mentioned below. Also, the measure of learning performance in traditional education is academic achievement, while in this study it was study progress. It could well be that these measures are too different to compare them.

The strengths of this study are multiple. The large data set provides high power related to the findings and decreases the risk of contracting a type-1 error. Next, this type of education and adult population has rarely been investigated, making these findings new and an important starting point for the field of DE. Last, a major strength is that the study controlled for a large number of possible confounders, eliminating possible spurious relationships. Next to strengths, this study also has limitations. First, it is observational and does not allow for causal inferences, although the design is longitudinal and the hypotheses were theory-driven. All independent measures are subjectively reported, imposing limitations on the interpretation. Subjective sleep duration, for example, can deviate from actual sleep duration. Second, study progress is a fairly large-grained measure, but the best one available to measure learning performance, as grades were not possible to use because a significant number of courses were evaluated with a pass/fail and not with a grade. Furthermore, comparing students based on achieved credits is most reliable considering the non-fixed and modular form of education given at the OUNL. Third, participants had a broad time frame (i.e., 9 weeks) to participate, possibly leading to betweensubject differences as some students did not yet start studying, while other were already ending their course. Last, participation took approximately 60 minutes and since participants could participate at their own pace (i.e., stop and return later) this could lead to some distortion. However, the last two points were tackled by the large dataset largely eliminating these possibly confounding factors. 


\section{Conclusion}

This study confirms the findings of a number of previous studies and strengthens the knowledge within the field of DE. First, chronotype did not predict study progress. Second, sleep duration did not predict study progress and third, sleep quality did not predict study progress. Despite the observational nature of this study and the limitations stated, these findings suggest that students participating in DE may benefit from this type of education as opposed to more traditional face-to-face higher education as the asynchrony problem does not seem to apply here since students can choose their own study schedule. 


\section{References}

Aloba, O. O., Adewuya, A. O., Ola, B. A., \& Mapayi, B. M. (2007). Validity of the Pittsburgh Sleep Quality Index (PSQI) among Nigerian university students. Sleep Medicine, 8(3), 266-270. doi:10.1016/j.sleep.2006.08.003

Bernt, F. M., \& Bugbee, A. C. (1993). Study practices and attitudes related to academic success in a distance learning programme. Distance Education, 14(1), 97-112. doi:10.1080/0158791930140108

Born, J. (2010). Slow-wave sleep and the consolidation of long-term memory. The World Journal of Biological Psychiatry, 11, 16-21. doi:10.3109/15622971003637637

Boschloo, A., Ouwehand, C., Dekker, S., Lee, N., de Groot, R., Krabbendam, L., \& Jolles, J. (2012). The relation between breakfast skipping and school performance in adolescents. Mind, Brain, and Education, 6(2), 81-88. doi:10.1111/j.1751-228X.2012.01138.x

Burkhalter, T. M., \& Hillman, C. H. (2011). A narrative review of physical activity, nutrition, and obesity to cognition and scholastic performance across the human lifespan. Advances in Nutrition, 2(2), 201S-6S. doi:10.3945/an.111.000331

Buysse, D. J., Reynolds, C. F., Monk, T. H., Berman, S. R., \& Kupfer, D. J. (1989). The Pittsburgh sleep quality index: A new instrument for psychiatric practice and research. Psychiatry Research, 28(2), 193-213. doi:10.1016/0165-1781(89)90047-4

Cappuccio, F. P., Taggart, F. M., Kandala, N.-B., Currie, A., Peile, E., Stranges, S., \& Miller, M. A. (2008). Meta-analysis of short sleep duration and obesity in children and adults. Sleep, 31(5), 619-26. Retrieved from http://www.ncbi.nlm.nih.gov/pubmed/18517032

Carskadon, M. A. (1990). Patterns of sleep and sleepiness in adolescents. Pediatrician, 17(1), 5-12. Retrieved from http://www.ncbi.nlm.nih.gov/pubmed/2315238

Centraal Bureau voor de Statistiek. (2014). Prognose bevolking 2012-2060. Retrieved from http://www.cbs.nl/nl-NL/menu/themas/bevolking/cijfers/default.htm

Cirelli, C., \& Tononi, G. (2008). Is sleep essential? PLoS Biology, 6, 1605-1611. doi:10.1371/journal.pbio.0060216

Crowley, S. J., Acebo, C., \& Carskadon, M. A. (2007). Sleep, circadian rhythms, and delayed phase in adolescence. Sleep Medicine, 8(6), 602-12. doi:10.1016/j.sleep.2006.12.002 
Curcio, G., Ferrara, M., \& De Gennaro, L. (2006). Sleep loss, learning capacity and academic performance. Sleep Medicine Reviews, 10(5), 323-37. doi:10.1016/j.smrv.2005.11.001

De Bie, S. E. (1987). Standaardvragen 1987: Voorstellen voor uniformering van vraagstellingen naar achtergrondkenmerken en interviews [Standard questions 1987: Proposal for uniformisation of questions regarding background variables and interviews]. Leiden: Leiden University Press.

Dewald, J. F., Meijer, A. M., Oort, F. J., Kerkhof, G. A., \& Bögels, S. M. (2010). The influence of sleep quality, sleep duration and sleepiness on school performance in children and adolescents: A meta-analytic review. Sleep Medicine Reviews, 14(3), 179-89. doi:10.1016/j.smrv.2009.10.004

Diamond, A. (2013). Executive functions. Annual Review of Psychology, 64, 135-68. doi:10.1146/annurevpsych-113011-143750

Díaz Morales, J. F., \& Sánchez-López, M. P. (2004). Composite and preferences scales of Morningness: Reliability and factor invariance in adult and university samples. The Spanish Journal of Psychology, 7(2), 93-100. doi:10.1017/S1138741600004790

Díaz-Morales, J. F., Escribano, C., Jankowski, K. S., Vollmer, C., \& Randler, C. (2014). Evening adolescents: The role of family relationships and pubertal development. Journal of Adolescence, 37(4), 425-432. doi:10.1016/j.adolescence.2014.03.001

Diekelmann, S., \& Born, J. (2010). The memory function of sleep. Nature Reviews. Neuroscience, 11(2), 114126. doi:10.1038/nrn2762

Durmer, J. S., \& Dinges, D. F. (2005). Neurocognitive consequences of sleep deprivation. Seminars in Neurology. Retrieved from http://www.ncbi.nlm.nih.gov/pubmed/15798944

Eppler, M. A., \& Harju, B. L. (1997). Achievement motivation goals in relation to academic performance in traditional and nontraditional college students. Research in Higher Education, 38(5), 557-573. doi:10.1023/A:1024944429347

Escribano, C., Díaz-Morales, J. F., Delgado, P., \& Collado, M. J. (2012). Morningness/eveningness and school performance among Spanish adolescents: Further evidence. Learning and Individual Differences, 22(3), 409-413. doi:10.1016/j.lindif.2011.12.008

Eurydice. (2011). Adults in Formal Education: Policies and Practices in Europe. doi:10.2797/51592

Ferrie, J. E., Shipley, M. J., Akbaraly, T. N., Marmot, M. G., Kivimäki, M., \& Singh-Manoux, A. (2011). Change in sleep duration and cognitive function: Findings from the Whitehall II Study. Sleep, 34(5), 56573. Retrieved from http://www.ncbi.nlm.nih.gov/pubmed/21532949 
Field, A. (2009). Discovering statistics using SPSS: And sex and drugs and rock " $n$ ” roll (Third edit). London: Sage.

Furnham, A., Monsen, J., \& Ahmetoglu, G. (2009). Typical intellectual engagement, Big Five personality traits, approaches to learning and cognitive ability predictors of academic performance. The British Journal of Educational Psychology, 79(Pt 4), 769-82. doi:10.1348/978185409X412147

Grady, C. L., \& Craik, F. I. (2000). Changes in memory processing with age. Current Opinion in Neurobiology, 10(2), 224-31. Retrieved from http://www.ncbi.nlm.nih.gov/pubmed/10753795

Gruber, R., Somerville, G., Enros, P., Paquin, S., Kestler, M., \& Gillies-Poitras, E. (2014). Sleep efficiency (but not sleep duration) of healthy school-age children is associated with grades in math and languages. Sleep Medicine, 15(12), 1517-1525. doi:10.1016/j.sleep.2014.08.009

Halpern, D. F. (1997). Sex differences in intelligence: Implications for education. The American Psychologist, 52(10), 1091-1102. doi:10.1037/0003-066X.52.10.1091

Horzum, M. B., Önder, İ., \& Beşoluk, Ş. (2014). Chronotype and academic achievement among online learning students. Learning and Individual Differences, 30, 106-111. doi:10.1016/j.lindif.2013.10.017

Jovanovski, D., \& Bassili, J. N. (2007). The relationship between morningness - eveningness preference and online learning. Biological Rhythm Research, 38(5), 355-365. doi:10.1080/09291010600950149

LimeSurvey Project Team / Carsten Schmitz. (2012). LimeSurvey: An Open Source survey tool. Retrieved from http://www.limesurvey.org

Miles, J. A. (2014). The impact of students' choice of time of day for class activity and their sleep quality on academic performance in multidisciplinary distance education courses. Retrieved from http://gradworks.umi.com/35/84/3584928.html

Möller-Levet, C. S., Archer, S. N., Bucca, G., Laing, E. E., Slak, A., Kabiljo, R., ... Dijk, D.-J. (2013). Effects of insufficient sleep on circadian rhythmicity and expression amplitude of the human blood transcriptome. Proceedings of the National Academy of Sciences, 110(12), E1132-E1141. doi:10.1073/pnas.1217154110

Nebes, R. D., Buysse, D. J., Halligan, E. M., Houck, P. R., \& Monk, T. H. (2009). Self-reported sleep quality predicts poor cognitive performance in healthy older adults. The Journals of Gerontology. Series B, Psychological Sciences and Social Sciences, 64(2), 180-187. doi:10.1093/geronb/gbn037

Neroni, J., Gijselaers, H. J. M., Kirschner, P. A., \& de Groot, R. H. M. (2015). The Adult Learning Open University Determinants (ALOUD) study: Biological and psychological factors associated with learning 
performance in adult distance education. British Journal of Educational Technology, Early view. doi:10.1111/bjet.12288

Önder, İ., Horzum, M. B., \& Beşoluk, Ş. (2011). Chronotype, learning approach, type/time of instruction and academic achievement of the university students. In L. Golovkin \& A. Maliszkewicz (Eds.), Circadian Rhythms (pp. 161-186). Nova Science Publishers, Inc.

Payne, J. D., Tucker, M. A., Ellenbogen, J. M., Wamsley, E. J., Walker, M. P., Schacter, D. L., \& Stickgold, R. (2012). Memory for semantically related and unrelated declarative information: The benefit of sleep, the cost of wake. PLoS ONE, 7(3), e33079. doi:10.1371/journal.pone.0033079

Radek, K. S., \& Kaprelian, J. (2013). Emerging adult sleep quality: Health and academic performance factors of assessment. Journal of Sleep Disorders \& Therapy, 2(2), 112. doi:10.4172/2167-0277.1000112

Randler, C., \& Frech, D. (2009). Young people’s time-of-day preferences affect their school performance. Journal of Youth Studies, 12(6), 653-667. doi:10.1080/13676260902902697

Randler, C., \& Truc, Y. (2014). Adaptation of the composite scale of morningness for parent report and results from kindergarten children. Swiss Journal of Psychology, 73(1), 35-39. doi:10.1024/1421-0185/a000121

Ribeiro, S., \& Stickgold, R. (2014). Sleep and school education. Trends in Neuroscience and Education, 3(1), 18-23. doi:10.1016/j.tine.2014.02.004

Roenneberg, T., Kuehnle, T., Pramstaller, P. P., Ricken, J., Havel, M., Guth, A., \& Merrow, M. (2004). A marker for the end of adolescence. Current Biology, 14(24), R1038-R1039. doi:10.1016/j.cub.2004.11.039

Roenneberg, T., Wirz-Justice, A., \& Merrow, M. (2003). Life between clocks: Daily temporal patterns of human chronotypes. Journal of Biological Rhythms, 18(1), 80-90. doi:10.1177/0748730402239679

Ryan, R. M., \& Deci, E. L. (2000). Self-determination theory and the facilitation of intrinsic motivation, social development, and well-being. The American Psychologist, 55(1), 68-78. Retrieved from http://www.ncbi.nlm.nih.gov/pubmed/11392867

Schmidt, C., Collette, F., Cajochen, C., \& Peigneux, P. (2007). A time to think: Circadian rhythms in human cognition. Cognitive Neuropsychology, 24, 755-789. doi:10.1080/02643290701754158

Seligman, M. E. P., Ernst, R. M., Gillham, J., Reivich, K., \& Linkins, M. (2009). Positive education: Positive psychology and classroom interventions. Oxford Review of Education, 35(3), 293-311. doi:10.1080/03054980902934563 
Short, M. A., Gradisar, M., Lack, L. C., \& Wright, H. R. (2013). The impact of sleep on adolescent depressed mood, alertness and academic performance. Journal of Adolescence, 36(6), 1025-1033. doi:10.1016/j.adolescence.2013.08.007

Singleton, R. A., \& Wolfson, A. R. (2009). Alcohol consumption, sleep, and academic performance among college students. Journal of Studies on Alcohol and Drugs, 70(3), 355-363. Retrieved from http://www.ncbi.nlm.nih.gov/pubmed/19371486

Sternberg, D. A., Ballard, K., Hardy, J. L., Katz, B., Doraiswamy, P. M., \& Scanlon, M. (2013). The largest human cognitive performance dataset reveals insights into the effects of lifestyle factors and aging. Frontiers in Human Neuroscience, 7(June), 292. doi:10.3389/fnhum.2013.00292

Taplin, M., \& Jegede, O. (2001). Gender differences in factors influencing achievement of distance education students. Open Learning: The Journal of Open and Distance Learning, 16(2), 133-154. doi:10.1080/02680510120050307

Taylor, D. J., Vatthauer, K. E., Bramoweth, A. D., Ruggero, C., \& Roane, B. (2013). The role of sleep in predicting college academic performance: is it a unique predictor? Behavioral Sleep Medicine, 11(3), 159-172. doi:10.1080/15402002.2011.602776

United Nations. (2012). Population Ageing and Development 2012. Retrieved from http://www.un.org/esa/population 


\section{Appendix}

\section{Correlation table of all variables included in the analyses}

\begin{tabular}{|c|c|c|c|c|c|c|c|c|c|c|c|c|c|c|c|c|c|c|c|c|c|c|c|c|}
\hline & & & $N=894$ & & & & & & & & & & & & & & & & & & & & & \\
\hline & Variable & Mean & SD & Range & 1. & 2. & 3. & 4. & 5. & 6. & 7. & 8. & 9. & 10. & 11. & 12. & 13. & 14. & 15. & 16. & 17. & 18. & 19. & 20 \\
\hline 1. & $\begin{array}{l}\text { Total work hours } \\
\text { per week }\end{array}$ & 30.94 & 12.11 & $0-84$ & 1 & - & - & - & - & - & - & - & - & - & - & - & - & - & - & - & - & - & - & - \\
\hline 2. & $\begin{array}{l}\text { Expected study } \\
\text { hours per week }\end{array}$ & 12.30 & 6.48 & $1-40$ & $-.198^{* *}$ & 1 & - & - & - & - & - & - & - & - & - & - & - & - & - & - & - & - & - & - \\
\hline 3. & Age in years & 36.15 & 10.45 & $18-68$ & -.003 & -.131 & 1 & - & - & - & - & - & - & - & - & - & - & - & - & - & - & - & - & - \\
\hline 4. & $\begin{array}{l}\text { Body mass index in } \\
\mathrm{kg} / \mathrm{m}^{2}\end{array}$ & 24.03 & 3.92 & $17-50$ & $.066^{*}$ & .028 & $.213^{* *}$ & 1 & - & - & - & - & - & - & - & - & - & - & - & - & - & - & - & - \\
\hline 5. & $\begin{array}{l}\text { Computer abilities } \\
\text { (percentage) }\end{array}$ & 42.72 & 5.81 & $16-52$ & $.170^{* * *}$ & $.071^{*}$ & $-.106^{*}$ & $.100^{*}$ & 1 & - & - & - & - & - & - & - & - & - & - & - & - & - & - & - \\
\hline 6. & $\begin{array}{l}\text { Expected finished } \\
\text { modules ( } 6 \text { months) } \\
\text { Alcohol }\end{array}$ & 2.26 & 2.29 & $0-14$ & -.035 & $.402 * *$ & $-.102^{*}$ & .009 & $.150 * *$ & 1 & - & - & - & - & - & - & - & - & - & - & - & - & - & - \\
\hline 7. & $\begin{array}{l}\text { consumption per } \\
\text { week }\end{array}$ & 3.11 & 4.61 & $0-28$ & .062 & -.027 & $.158^{* * *}$ & .006 & .040 & -.002 & 1 & - & - & - & - & - & - & - & - & - & - & - & - & - \\
\hline 8. & $\begin{array}{l}\text { Life satisfaction } \\
\text { (percentage) }\end{array}$ & 25.48 & 5.43 & $5-35$ & $.121^{* *}$ & $-.146^{* *}$ & $.123 * *$ & $-.067 *$ & -.002 & -.024 & .020 & 1 & - & - & - & - & - & - & - & - & - & - & - & - \\
\hline 9. & $\begin{array}{l}\text { Chronotype } \\
\text { (MSF }\end{array}$ & 3:49 & $0: 55$ & $\begin{array}{l}1: 15- \\
7: 00\end{array}$ & .047 & $.115^{* *}$ & $-.275 * *$ & -.060 & .060 & $.069 *$ & $.150 * *$ & $-.178 * *$ & 1 & - & - & - & - & - & - & - & - & - & - & - \\
\hline 10. & $\begin{array}{l}\text { Sleep duration } \\
\text { (work) }\end{array}$ & 7:56 & $0: 56$ & $\begin{array}{l}5: 00- \\
11: 00\end{array}$ & $-.258^{* *}$ & .004 & $-.139 * *$ & $-.076^{*}$ & -.036 & -.039 & $-.070^{*}$ & -.033 & .060 & 1 & - & - & - & - & - & - & - & - & - & - \\
\hline 11. & $\begin{array}{l}\text { Sleep duration } \\
\text { (free) }\end{array}$ & 8:30 & $1: 07$ & $\begin{array}{l}5: 00- \\
12: 00\end{array}$ & $-.163^{* *}$ & -.008 & $-.261 * *$ & $-.121^{* *}$ & $-.076 *$ & -.005 & $-.103^{*}$ & .008 & -.008 & $.431^{* *}$ & 1 & - & - & - & - & - & - & - & - & - \\
\hline 12. & $\begin{array}{l}\text { Sleep duration } \\
\text { polynomial (work) }\end{array}$ & 0.88 & 1.46 & $0.01-9.44$ & $-.096 *$ & $.168^{* *}$ & $-.076^{*}$ & .026 & .017 & .020 & -.005 & $-.110^{* *}$ & $.162^{* * *}$ & $.102 *$ & $.078^{*}$ & 1 & - & - & - & - & - & - & - & - \\
\hline 13. & $\begin{array}{l}\text { Sleep duration } \\
\text { polynomial (free) }\end{array}$ & 1.23 & 1.89 & $\begin{array}{l}0.00- \\
12.29\end{array}$ & -.020 & .040 & $-.090^{*}$ & -.010 & .028 & .040 & .007 & $-.104 *$ & $.165^{* *}$ & -.030 & -.003 & $.267^{* *}$ & 1 & - & - & - & - & - & - & - \\
\hline $\begin{array}{l}14 . \\
15 .\end{array}$ & $\begin{array}{l}\text { Sleep quality } \\
\text { Sex }(0=\text { male })\end{array}$ & - & - & - & $\begin{array}{c}.021 \\
-.239 * *\end{array}$ & $\begin{array}{l}.011 \\
-.097 *\end{array}$ & $\begin{array}{l}.081 * \\
-.063\end{array}$ & $\begin{array}{l}-.074 * \\
-.155 * *\end{array}$ & $\begin{array}{l}.064 \\
.233^{* *}\end{array}$ & $\begin{array}{l}.045 \\
-.064\end{array}$ & $\begin{array}{l}-.002 \\
-.163^{* *}\end{array}$ & $.189 * *$ & -.044 & $\begin{array}{l}.028 \\
102 * *\end{array}$ & -.024 & -.033 & -.032 & 1 & i & - & - & - & - & - \\
\hline 16. & $\begin{array}{l}\text { Sex (0=male) } \\
\text { Nationality } \\
\text { (1=Dutch) }\end{array}$ & - & - & - & $-.077^{*}$ & -.051 & .049 & .018 & -.024 & -.031 & $\begin{array}{l}-.103 \\
.010\end{array}$ & $\begin{array}{l}.051 \\
.066^{*}\end{array}$ & $\begin{array}{l}-.134^{* *} \\
-.009\end{array}$ & $\begin{array}{l}.198^{* * *} \\
.080^{*}\end{array}$ & $\begin{array}{l}.198^{* *} \\
.021\end{array}$ & $\begin{array}{l}-.083^{*} \\
-.016\end{array}$ & $\begin{array}{l}.013 \\
-.022\end{array}$ & $\begin{array}{l}-.031 \\
.007\end{array}$ & $\begin{array}{c}1 \\
.021\end{array}$ & 1 & - & - & - & - \\
\hline 17. & $\begin{array}{l}\text { Native language } \\
\text { (1=Dutch) } \\
\text { Educational level }\end{array}$ & - & - & - & -.002 & -.036 & .027 & -.036 & -.032 & .024 & $.096 *$ & -.008 & -.041 & $.091 *$ & . 042 & -.058 & .034 & -.041 & -.030 & $.127^{* *}$ & 1 & - & - & - \\
\hline 18. & $\begin{array}{l}\text { dummy for high } \\
\text { (1=high) } \\
\text { Educational level }\end{array}$ & - & - & - & -.006 & $.071^{*}$ & $-.103^{*}$ & .055 & .032 & .054 & .031 & .012 & $.066^{*}$ & .056 & $.080^{*}$ & .022 & .002 & .023 & .024 & $.193 * *$ & .064 & 1 & - & - \\
\hline 19. & $\begin{array}{l}\text { dummy for } \\
\text { university } \\
\text { (1=university) } \\
\text { Studd motive }\end{array}$ & - & - & - & .036 & $-.170^{* *}$ & $.152 * *$ & $-.066^{*}$ & -.030 & $-.073^{*}$ & .027 & $.128^{* *}$ & $-.068^{*}$ & -.023 & $-.077 *$ & $-.087 *$ & -.044 & .052 & .028 & $-.113^{* *}$ & -.047 & $-.727^{* *}$ & 1 & - \\
\hline 20. & $\begin{array}{l}\text { Study motive } \\
(0=\text { personal, } \\
1=\text { professional) }\end{array}$ & - & - & - & -.029 & . 051 & -.063 & .000 & -.010 & $.073 *$ & -.041 & -.051 & .000 & .014 & . .020 & -.012 & .009 & .005 & $.097 *$ & -.049 & .022 & $-.144^{* *}$ & $.156^{* *}$ & 1 \\
\hline
\end{tabular}




\section{Online appendix}

The covariates measured in this study are explained in more detail in this appendix. In case English questionnaires were used, items were translated from English into Dutch by a native Dutch speaker. To make sure the translation was correct, the items were translated back by a bilingual English/Dutch-speaking person. Adjustments were made where necessary. The list below provides information on the covariates, how and why they were measured, were they originated from and how they were calculated, if relevant. The variables are:

- Age was measured as memory performance declines with increasing age (Grady \& Craik, 2000), possibly hampering learning efficiency. It was measured using the reported date of birth and was calculated in years (i.e., not rounded to integers).

- Sex was measured as sex differences in intelligence (e.g. on the domains of memory, reasoning and science) have been found which could influence study progress. There are intellectual domains where males excel females (e.g., spatial reasoning) and vice versa (e.g., verbal fluency) (Halpern, 1997).

- $\quad$ Number of working hours/week was measured as more working hours could lead to less study-time and consequently less study progress (Eppler \& Harju, 1997). However, research has also found that workers with fewer than 20 work hours/week perform more poorly than their counterparts working more (Taplin \& Jegede, 2001). It was calculated by adding the hours spent on work (i.e., either from wage labor or as an independent entrepreneur) and volunteering together.

- Expected average of number of study hours/week to be invested was measured as more time invested is likely to lead to better results (Bernt \& Bugbee, 1993). This was reported in hours by the participants.

- Nationality was measured as education is not 'culture free' and as such non-Dutch people could have more difficulties with the more cultural elements in the educational system. It was measured by asking whether the participant was Dutch. If not, the participant could enter his or hers nationality. These nationalities were inspected and if necessary recoded (e.g., some participants entered a region of the Netherlands as their nationality, which was recoded into Dutch). Finally, one variable indicated whether the participant was Dutch or not.

- $\quad$ Native language was measured as non-Dutch speakers could have more difficulties with the language of study. It was measured by asking whether the participants’ native language was Dutch. If not, the participant could enter his or hers native language. These manually entered data were inspected and if necessary recoded (e.g., some participants entered a regional Dutch dialect as their native language, 
which was recoded into Dutch). Finally, one variable indicated whether the participants' native language was Dutch or not.

- Body mass index was measured as a large meta-analysis shows an increased risk of obesity for short sleepers (Cappuccio et al., 2008), which could lead to a decrease in cognitive performance (Burkhalter \& Hillman, 2011). It was computed from self-reported weight and height, in kilogram and cm, respectively. It was computed by the following equation: $\mathrm{BMI}=$ weight $/$ height $^{2}$.

- Level of education was measured as previous level of education has been found to be a significant predictor of academic success for adult DE students (Bernt \& Bugbee, 1993). It was measured as an eight level ordinal variable following de Bie (1987). This is typical in Dutch research as these levels correspond with the education given in the Netherlands. These eight levels were: (1) primary general education, (2) lower vocational education, (3) secondary general education, (4) secondary vocational education, (5) secondary higher education, (6) higher vocational education, (7) higher general education / University education, (8) Post-graduate / post-university education. These eight categories were dummy coded into low (i.e., option 1, 2, 3, and 4), high (i.e., option 5 and 6), and university level (i.e., option 7 and 8), with low as reference category.

- $\quad$ Computer abilities was measured as students use an electronic learning environment which could be a disadvantage when one is not very computer literate or fluent. It was measured via a self-developed Dutch questionnaire mapping attitude, confidence, and skills towards the use of a computer. Five items involved attitude, three items on confidence, and five items on skills. Six items were reversed and a four-point scale was used ranging from fully disagree to fully agree. The minimum score was 13 and the maximum score was 52. A higher score indicated better computer abilities.

- Study motive was measured as intrinsic motivation has been found to be a better motivator for learning than extrinsic triggers (Ryan \& Deci, 2000). It was indicated as either personal or professional after rescoring. The original question asked for the most important motive to start studying. Answer options were: (1) to better fulfill the requirements in my current job, (2) to enhance my chances of a new job, (3) because studying is a good way of spending leisure time, (4) I want to develop my (intellectual) capacities, (5) I want to function better at a societal or managerial level, (6) I want to know more about the subject of this course, (7) I want to develop within the respective scientific field, (8) other. Options 3, 4, 6, and 7 were recoded as a personal motive, the others as a professional motive. Participants who entered 'other' were recoded to personal or professional based on their answer. 
- Study goal was measured as it provides a clear estimation of the expectation and hence the intention of the study progress to be made. It was measured as the expected number of completed modules after 6 months, which was indicated by the participants.

- Alcohol consumption was measured as this has been found to influence study progress (Singleton \& Wolfson, 2009). It was measured as the number of standard glasses on work days and free days, which was calculated to a weekly total.

- $\quad$ Life satisfaction was measured using the 'Satisfaction with life' scale of Diener, Emmons, Larsen \& Griffin (1985) as more satisfaction has been found to be synergistic with better learning (Seligman, Ernst, Gillham, Reivich, \& Linkins, 2009). 